\title{
La Mirada Psicosocial en un Contexto de Guerra I ntegral de Desgaste
}

\section{Cecilia Santiago Vera}

El Estado Mexicano vive una de las peores crisis a su interior, capaz de asesinar a estudiantes en 1968, es hoy capaz de imponer una ocupación policiaco-militar a la capital del estado de Oaxaca y de permitir más de 19 asesinatos de activistas, profesores y líderes campesinos. Oaxaca es uno de los estados con mayor presencia de pueblos originarios y con los índices de marginación más elevados. En mayo de este mismo año 2006, Atenco sufrió la misma violencia de Estado.

¿Cómo pueden los pueblos sobrevivir ante tanta injusticia? El presente trabajo trata de una de las formas contemporáneas de control social, la guerra integral de desgaste desarrollada durante los últimos doce años en Chiapas México, estrategia utilizada desde 1994 como respuesta al levantamiento indígena zapatista. Igualmente da explicación de cómo la población durante estos años, rompe con la inercia de la violencia y promueve valores que le permiten continuar su resistencia y su búsqueda por una vida digna.

En este contexto la praxis desde una psicología que mira abajo y a la izquierda tiene desafíos y contradicciones. Reflejaré algunos de los aprendizajes que a lo largo de doce años se desprenden de una práctica basada en la mirada psicosocial.

Finalmente me referiré al papel histórico que la psicología social de la liberación tiene, desde la mirada psicosocial, a nuestra realidad latinoamericana en grande sufrimiento. A la vez de reconocer el compromiso histórico y urgente por ofrecer estas aportaciones a los distintos actores sociales que empujan valientemente hacia un nuevo mundo de relaciones basadas en una justicia reparadora, que buscan un modo organizativo de la sociedad creativo y basado en los proyectos de vida de la propia población, es decir, que respete la autonomía y la vida plena de los pueblos.

\section{Chiapas -- Doce Años de Guerra, Doce Años de Resistencia}

\section{Guerra I ntegral de Desgaste}

En una primera fase, en el año 1994 las tropas actuaron con todo para 'acabar' con el enemigo: los indígenas subversivos. Más adelante se fue consolidando otro objetivo políticamente menos costoso: transformar el tejido social donde los rebeldes tenían presencia. Romper la vida cotidiana de estas comunidades, las más pobres y marginadas del país. Su propósito fue realizar acciones violentas útiles para mantener el control social pero a la vez que tuvieran el menor costo político.

¿Qué conseguirían con este plan? Consolidar nuevas relaciones sociales con nuevos actores en las regiones zapatistas, los militares y paramilitares. Instituyendo nuevas pautas sociales que buscan el agotamiento de la fuerza organizativa del pueblo. Apostando al cansancio de la gente y logrando el establecimiento de la institucionalidad desde la federación. Que finalmente impidiera el desarrollo del proyecto de nación que promovió el EZLN desde su primera declaración de la selva lacandona. Es decir, impedir 
que la fuerza de este movimiento social amplio se extendiera por todo el país. (PérezSales, 2002)

Esta estrategia les tomaría tiempo y varias acciones como:

- La ocupación militar en las comunidades zapatistas

- Promover el proceso de paramilitarización en zonas geográficamente estratégicas

- Destruir el tejido económico de los "alzados"

- Un diálogo circular entre el EZLN y el Gobierno Federal, sin resultados a corto plazo

- Mantener el control electoral y el poder del estado de Chiapas con el PRI y en el 2000 con la alianza de partidos. Un cambio que mantendría todo igual.

- El control de medios de comunicación

- Efectuar labores de "inteligencia"

- Domesticar al poder legislativo estatal al servicio del gobernador

- Mantener el aparato judicial intacto

Para explicar mejor esta estrategia retomo el esquema de análisis de una guerra contemporánea que hace Pérez-Sales. ${ }^{1}$ Esto significa que en los últimos 12 años el gobierno federal y el ejército federal mexicano han implementado en Chiapas una guerra de desgaste, es decir, "una guerra realizada por sucesivos operativos puntuales que van asfixiando al enemigo en los terrenos político, económico y militar ${ }^{\prime 2}$. Evitando en lo posible acciones espectaculares para no llamar la atención internacional.

Este tipo de guerra busca quitar la fuerza de la gente y desgastar los procesos organizativos y las personas. Uno de sus objetivos es crear un clima de miedo que conduzca a la inmovilidad y a la resignación social.

Para el año 2000 esta estrategia militar cambia de rostro. Las elecciones oficiales para gobernador en agosto de este año dan como ganador por primera vez en Chiapas al candidato de una coalición de oposición. Su lema de gobierno fue "uno con todos". Durante sus seis años de gobierno enfatizó que la paz es fruto del desarrollo. Guardó distancia del conflicto armado y delegó la solución al gobierno federal. Dicho gobernador no cumplió sus promesas de campaña y se convirtió en un represor con traje nuevo contra el movimiento indígena levantando en armas en 1994 y contra el movimiento social que cuestionara su investidura y rechazara sus condiciones. La estrategia de guerra integral se vio reforzada por el liderazgo de un gobernador que quiere el control total de su población. El ejército mantiene hasta la fecha estrecho vínculo e influencia en lo que aparentemente son las políticas públicas.

El objetivo de su estrategia ha sido posibilitar la inversión externa, edificar los planes de desarrollo previstos y acotar el activismo del EZLN así como de sus bases populares. Nunca ha sido su intención resolver de raíz lo que origina la inconformidad social. En este año 2006 se llevaron a cabo nuevas elecciones y la continuidad de este mandato está asegurada y con ella la zozobra para millones de habitantes. El gobierno federal por su parte guarda silencio y se ocupa únicamente de mantenerse en el poder y secundar planes económicos neoliberales.

\footnotetext{
${ }^{1}$ Pérez-Sales et al. Ahora apuestan al cansancio. Chiapas: fundamentos psicológicos de una guerra contemporánea. México. 2002

${ }^{2}$ Idem. P. 249
} 
Las consecuencias psicológicas entre la población son de extrema gravedad. Existe un daño moral y traumático entre la población, un daño económico y la afectación de los sectores que han sido entrenados para matar. Las consecuencias psicosociales se expresan en la ruptura del tejido social chiapaneco, la división de las comunidades, el enfrentamiento, la polarización social y el ataque directo a la identidad étnica maya y zoque.

Todos hemos sido afectados de una u otra manera por la guerra. Las respuestas ante tales circunstancias de dolor y miedo han sido variadas según la implicación más o menos directa de situaciones de peligro. Según las características personales, grupo de edad, postura política, región donde habita y contexto. Cada sector de la población ha tenido una respuesta diferente. Modos de afrontamiento van desde la resignación hasta la rebeldía.

\section{Afrontamiento y Resistencia de la Población}

El "afrontamiento incluye tanto pensamientos y emociones como conductas de resolución de problemas." ${ }^{3}$ Por ejemplo pensar en planes para solucionarlos o buscar significado a la experiencia vivida. En lo emocional, compartir sus experiencias o suprimir los sentimientos. "El afrontamiento conductual es lo que la gente hace para enfrentar el problema como la búsqueda de información y apoyo material o la pasividad. ${ }^{14}$

Los seres humanos somos capaces de afrontar situaciones graves y adversas. En Chiapas encontramos este esfuerzo centrado en salir adelante a pesar de las adversidades, la ocupación militar, las divisiones comunitarias, el encarcelamiento injusto, la represión.

Hay una guerra, vivimos en la polarización, pobreza extrema, sin servicios básicos. Pero hay una fuerza extraordinaria que impulsa a las personas hacia la respuesta activa, creativa, construyendo y transformando su historia.

Carmelo Vázquez llama optimismo inteligente a los recursos positivos que toda persona tiene para afrontar cualquier obstáculo. Immanuel Wallerstein plantea el concepto de utopística como "el análisis de las utopías posibles, sus limitaciones y los obstáculos para alcanzarlas" 5 .

Este enfoque de un análisis social focalizado en lo positivo puede llevarnos a la creatividad que Johan Galtung ${ }^{6}$ transmite para llegar a transformar y trascender los conflictos. Conflictos que genera cualquier ambiente de violencia e impunidad como el que vivimos en nuestro país.

Debemos potenciar nuestras virtudes, las virtudes populares de las que habló Ignacio Martín Baró, al referirse a las tareas de la psicología en contextos de guerra ${ }^{7}$. Recordemos

\footnotetext{
${ }^{3}$ Martín-Beristain, C. Enfrentando las tragedias. En Psicología social y violencia política, p.144. ECAP. Guatemala. 2001.

${ }^{4}$ Idem. P. 145.

${ }^{5}$ Wallerstein, I. Conocer el mundo, Saber el mundo. El fin de lo aprendido. Una ciencia social para el siglo XXI. P. 246. Siglo XXI editores. $2^{\mathrm{a}}$ edición en español. México. 2002.

${ }^{6}$ Galtung, J. Transformar y trascender los conflictos. Edit. Quimera. México. 2004.

${ }^{7}$ Entrevista con el Dr. Ignacio Martín Baró. En Ignacio Dobles, Psicología Social desde Centroamérica: retos y perspectivas. Revista Costarricense de Psicología, 1986, número 8 y 9. p.74
} 
sus preguntas ¿Qué hace que en condiciones límites o en condiciones muy drásticas la gente sobreviva?, ¿Cuáles son las virtudes que tienen los pueblos, los sectores populares?

Inmanuel Wallerstein también se pregunta "¿Qué es lo que moviliza el apoyo masivo? Y responde, "No se puede decir que sea el grado de opresión. Ante todo, éste suele ser una constante y por consiguiente no explica por qué las personas que se movilizaron en Tiempo Dos no se habian movilizado en Tiempo Uno. Además, con mucha frecuencia la represión aguda funciona, impidiendo que los menos audaces estén dispuestos a participar activamente en el movimiento. No, lo que moviliza a las masas no es la opresión, sino la esperanza y la certeza - la creencia en que el fin de la opresión está cerca y que un mundo mejor es realmente posible" ${ }^{8}$.

A continuación menciono algunas de las respuestas sociales que considero han roto con la espiral de violencia en Chiapas. A la vez que han permitido caminar por rumbos de construcción y resistencia. Retomaré modos de actuación sin detenerme a describir el sector de la población que lo desarrolla.

\section{La Resistencia Ante la Adversidad}

Desde la mirada de la psicología social podemos decir que la gente sufre las consecuencias de su lucha por la dignidad, pero no se queda inmovilizada sintiéndose víctima por la violencia de Estado, ese actor externo que busca aniquilarlos, sino que se reconocen como sujetos activos que pueden transformar su realidad.

"Existe una fuerza, cuyo mecanismo no comprendemos plenamente y que parece operar en la mayor parte de las personas con el fin de proteger y promover su salud mental aun en las condiciones más adversas" ${ }^{\prime \prime}$. Esa es la fuerza que encontramos en Chiapas. Personas que viven en la violencia y son capaces de salir y buscar rutas que les den vida.

Es esa capacidad de resistencia histórica de nuestros pueblos de haber vivido el sufrimiento por generaciones. Esta historia que ha permitido desarrollar socialmente una capacidad de aguante o resistencia sólida. Resistencia que permite soportar el dolor más agudo. Así lo confirma Carlos Martín-Beristain, diciendo que "las poblaciones afectadas por la violencia y las culturas tradicionales incluyen también una enorme sabiduría sobre la forma de enfrentar los problemas. "10

Es la fuerza espiritual y el profundo amor al semejante que encontramos entre la gente. Es también su compromiso sociopolítico que los impulsa, un afrontamiento cognitivo e ideológico ${ }^{11}$. Esa capacidad de implicarse para tratar de cambiar la realidad, un compromiso que va acompañado de una reinterpretación positiva de lo ocurrido, que empuja a seguir adelante.

\section{La Búsqueda de Una Vida Digna}

Es la búsqueda de la felicidad la que nos mueve como humanidad, dicen José Antonio Marina y María Válgoma en su libro La lucha por la dignidad, teoría de la felicidad política.

\footnotetext{
${ }^{8}$ Wallerstein, I. Op. Cit. P. 29

${ }^{9}$ Scott Peck, M. La nueva psicología del amor. EMECÉ. Argentina. 1986. P. 248 y 249.

${ }^{10}$ Martín-Beristain, C. Op. Cit. P. 147

${ }^{11}$ Martín-Beristain, C. Op. Cit.
} 
Es ese impulso el que nos mueve a dar pasos en la defensa de nuestra dignidad y nos permite encaminar nuestros pasos en esta lucha incansable. Como la afirmación que en Chiapas se convirtió en lema "queremos una paz con justicia y dignidad". O la frase zapatista "por la humanidad y contra el neoliberalismo".

Se trata de rescatar no solamente la palabra dignidad sino todo el significado que la encierra y el valor para hacerla realidad.

Para el mundo tseltal, nos dice Antonio Paoli, la paz "supone la dimensión sagrada y perfecta del silencio."12 La paz o slamalil k'inal es un factor clave para que "haya lekil kuxlejal que significa la vida buena por antonomasia. No es una utopía porque no se refiere a un sueño inexistente. No, el lekil kuxlejal existió, se ha degradado pero no se ha extinguido y es posible recuperarlo. No sólo pertenece a este mundo, también al más allá. "13 Y es esta "idea de perfección del lekil kuxlejal (vida buena) el fundamento moral de la vida cotidiana", ${ }^{14}$ "que supone una integración perfecta entre la sociedad y la naturaleza's5.

\section{La Organización}

La organización social, permite "modalidades eficaces de prevención y enfrentamiento de los problemas ${ }^{\prime 26}$ dice I gnacio Dobles. Es la base sobre la cual la población construye. Es el tejido social por donde camina la vida.

Existen estructuras organizativas maduras que han sobrevivido todo. Otras más recientes pero todas dando cobijo, apoyo mutuo, respaldo, integración, soporte, identidad. Cada una con sus propios retos al interior y sus incoherencias como toda construcción social.

Quiero resaltar una característica especial. La capacidad que tienen algunos movimientos que van transformándose en función del contexto y de su propia gente. Sólo para dar un ejemplo, la desmilitarización del EZLN dando paso a la participación activa y pública de su población civil creando las J untas de Buen Gobierno.

\section{El Uso de la Memoria}

La memoria entendida como un recurso ancestral que ayuda a saber quienes somos como pueblo, como colectivo. La tradición oral que transmite valores y sabiduría. La virtud de recordar sin obsesión. En el libro abusos de la memoria de Tzvetan Todorov dice "/a recuperación del pasado es indispensable; lo cual no significa que el pasado deba regir el presente, sino que, al contrario éste (el presente) hará del pasado el uso que prefiera. "17 Recordar no para quedarse en el pasado sino para aprender de él y encontrar respuestas hacia la transformación del presente, de tal manera que al recuperar nuestros recuerdos, aún dolorosos, no podrán ser olvidados del todo pero sí podremos dejarlos de lado perdiendo su efecto devastador sobre las personas.

\footnotetext{
${ }^{12}$ Paoli, A. Acercamiento a la sabiduría de los tseltales. UAM-Xochimilco. México. 1999. P. 71

${ }^{13}$ Idem. P.71

${ }^{14}$ Idem. P.71

${ }^{15}$ Idem. P.75

${ }^{16}$ Dobles, I. Hacer psicología en Centroamérica. En Subjetividad y política. ILAS. Chile. 1997. P. 23

${ }^{17}$ Todorov, T. Los abusos de la memoria. P. 25. Paidós Asterisco. España. 2000. 1ª edición en francés 1995.
} 
Traigo aquí el caso de un grupo de desplazados que a un año de estar fuera de casa exigían a su organización volver de inmediato y de la manera que fuera. Sus líderes les propusieron hacer talleres en donde repasaran lo ocurrido durante la salida forzada por paramilitares y lo que habían vivido en este último año. Ellos tenían claro que de esta manera se harían más concientes de la estrategia paramilitar y la importancia de tomar una decisión de retorno más pensada junto con toda la organización. Así sucedió, el retorno se llevó años después de manera conjunta.

\section{Los Sueños. Una Forma de Hacer Análisis}

Es la intuición desarrollada que se expresa en algunas personas que al amanecer tratan de interpretar los que soñaron por la noche. Sueños en los cuales han encontrando signos que permiten prever situaciones de peligro. Tomar decisiones en función de este análisis les ha permitido hasta salvar vidas. Además de encontrar respuestas ante momentos de emergencia por ejemplo a dónde refugiarse. Un líder de una comunidad de la organización Sociedad Civil las Abejas, cuenta que salían corriendo ante los disparos de los paramilitares y al preguntarse a dónde nos vamos, él recordó el sueño que tuvo por la noche. En el cual él estaba de viaje y en el cielo aparecían unas letras escritas que decían el nombre de una comunidad vecina. "Así fue que decidimos ir para allá", me dijo. ${ }^{18}$

\section{La Participación Activa de las Mujeres}

Las acciones de las mujeres se han dado en todos los ámbitos, tanto públicos como privados. Sus capacidades para enfrentar las dificultades más grandes en el hogar, con el cuidado de los hijos y dentro de su participación política en la sociedad. Negándose a la subordinación y autoafirmándose en su papel histórico en las transformaciones sociales.

Ahí tenemos a las miles de compañeras que pasan horas delante del fogón haciendo las tostadas para los hombres que están en la montaña. Las compañeras que deciden no casarse por voluntad para tener libertad, dando ejemplo y los pasos que más adelante otras generaciones disfrutarán, como es la convivencia con una pareja que las comprenda y respete. Las compañeras de la comunidad de X'oyep que se enfrentaron contra los militares y evitaron la ocupación de su poblado. En fin muchos, muchos casos más.

\section{Acciones de Lucha No Violenta}

Evitando la confrontación directa con el Ejército Federal. Como el caso de las comunidades que se autodesplazaron en 1995 en las cañadas de Ocosingo. La capacidad de detener la violencia con formas de resistencia pasiva: los cinturones de mujeres y niños rodeando las entradas de sus comunidades como intentos por mantener desmilitarizadas las comunidades. El valor de enfrentarse a las armas, a las tanquetas, a los Hummers.

Las movilizaciones pacíficas, como las marchas ocurridas en Tuxtla Gutiérrez, la capital del estado, una en marzo del 2005 con más de 50 mil maestros. La otra el 10 de mayo de ese mismo año con más de 80 mil maestros incluyendo el sindicato de salud, 27 sindicatos más y organizaciones sociales. Exigiendo respeto al derecho de asociación sindical,

\footnotetext{
${ }^{18}$ Comunicación personal. Acteal 1998.
} 
cumplimiento de los compromisos hechos por el gobierno del estado, libertad de los presos políticos.

\section{La Resolución Positiva de Conflictos Comunitarios}

Esa capacidad de asumir los conflictos como una realidad y la responsabilidad que todos tenemos para transformarlos. Es la capacidad de cambiar personal y colectivamente. Es darse la oportunidad de aclarar malos entendidos, de mejorar la comunicación, de comprender al otro, de acercarme a mi 'enemigo', de ceder o de exigir.

Es una lucha por afirmar un espacio civil y de reconstrucción social en medio del conflicto. Esfuerzos que otorgan espacio a la palabra antes que a los golpes, antes que a los asesinatos. Podemos decir que es un movimiento que con fuerza empuja a caminar integrándonos en la diferencia.

Gracias a esta opción de la población no hemos regado ríos de sangre como en pasadas décadas en países vecinos. Han sido muchos nuestros muertos pero la polarización social aún no nos ha destruido por completo.

\section{La Lucha Contra la I mpunidad Promoviendo Una J usticia Reparativa}

El principal problema que impide el desarrollo de un nuevo proyecto de nación en México es, sin duda, la impunidad. Cambiar esta inercia es un gran reto. Considero que podemos ver una pequeña luz en el camino hasta él cuando encontramos en algunas regiones del estado autoridades nombradas por sus comunidades. Son las Juntas de Buen Gobierno que lentamente van ganando legitimidad entre toda la población. Cuyo papel es por un lado servir de mediadores y por otro ser líderes formales que promueven juicios. En donde la verdad se privilegia y el reconocimiento de la falta o delito se purga aceptándolo, pidiendo perdón y reparando el daño cometido.

Este es un modelo en movimiento que va retomando valores ancestrales y va relacionándose con la administración de justicia del Estado Mexicano. Por citar un ejemplo la resolución de conflictos agrarios añejos que mantienen en tensión y continua venganza diferentes organizaciones indígenas y campesinas.

\section{El Tiempo Largo}

La incansable decisión de optar por construir a largo plazo, sin esperar resultados inmediatos. Con la actitud del sembrador que no está seguro que recogerá los frutos pero sabe que alguien más adelante los necesitará. Seguir el ritmo propio dejando de lado el calendario electoral, por ejemplo. Esta es la virtud de nuestros mayas, zoques y de todos nuestros pueblos originarios en México y en el continente.

\section{Aprendizajes de Una Práctica Basada en la Mirada Psicosocial}

Mi práctica se ha desarrollado desde el ámbito de los derechos humanos, la transformación positiva de conflictos, la salud, el compromiso político y actividades de solidaridad. Trabajando en el estado de Chiapas, con población bajo ocupación militar y 
con presencia paramilitar; población que ha sufrido catástrofes después del paso de huracanes; población que vive con las consecuencias de lo que implica la frontera sur de México; población rural y urbana que viven en condiciones de violencia estructural; y población bajo la violencia política, la represión política del Estado Mexicano, la persecución y la cárcel.

Las intervenciones han sido mediante: entrevistas, asesorías, conversaciones, reuniones, talleres, cursos y diplomados, consultas psicoterapéuticas, conferencias, visitas, asambleas, encuentros, grupos de apoyo mutuo, haciendo investigación, sistematización, usando la radio o materiales escritos.

Este recorrido abarca ya doce años de trabajo. Muchas de las preguntas planteadas han encontrado respuesta, otras se mantienen asiduas e insistentes. Cada una ha significado una ruptura importante en mi vida personal y en el modo de acercarme a la realidad. Me referiré a continuación a dos de ellas.

\section{1) Transitar de la psicología dominante-individualista a una psicología social de la liberación de nuestros pueblos.}

Mi práctica parte de una psicología que es parte del conocimiento legitimado como científico. Por lo tanto son bases establecidas como únicas pero que al confrontarse con mi realidad laboral en pleno conflicto armado, no tiene respuestas que aportar. Es así como comienzo una práctica desde la complejidad de la realidad concreta del desposeído. Desde las clases peligrosas comienza la búsqueda de respuestas o conocimientos para tales desafíos.

Esta posición me lleva a romper las ataduras de la psicología dominante. Reconociendo que nuestra formación universitaria es heredera de una ciencia hija del capitalismo. Nace de una ideología dominante que aún busca mantenernos bajo su control. Dejo atrás poco a poco las máscaras aprendidas de: objetividad, neutralidad, rol de experta, énfasis en el conocimiento científico. Para acercarme de lleno a los planteamientos recogidos en la psicología social de la liberación.

Me encontré en diferentes momentos en un proceso de resignificar lo aprendido desde la psicología dominante ubicando sus aportes y límites de mi relación frente a ella. A la vez resignificaba los otros saberes, tanto de otras disciplinas como de los modos populares y culturales de conocimiento.

Aprendí que la investigación es parte de la práctica, ya que una y otra van de la mano. La investigación es una herramienta para acercarnos a nuestra unidad de análisis. Nos ayuda a comprenderla para hacer propuestas de intervención más adecuadas. Pero nuestra realidad latinoamericana nos exige ir más allá de los esquemas de investigación académico-formales. En un esfuerzo por liberarnos de estos modos rígidos, buscamos otras metodologías y encontramos que este recorrido de estudio para aprender de la experiencia se encuentra también en diferentes metodologías de sistematización. Que tienen gran importancia para sacar lecciones a partir de nuestras propias experiencias, motivarnos a escribirlas y compartir nuestros resultados. "Nos ayudará a producir nuevos conocimientos para mejorar nuestras prácticas, nuestras acciones o nuestros proyectos y 
sus resultados ${ }^{\prime 19}$ ya que nuestro objetivo es mejorar nuestra práctica cotidiana para ir empujando las transformaciones sociales específicas.

Desde esta perspectiva encontré que no era suficiente calmar las consecuencias en la población ante la violencia estructural, política, la guerra. Sino que nuestra tarea también es participar del doloroso recorrido hacia la liberación de nuestros pueblos. De tal manera poder contribuir a que seamos más fuertes y sabios para mantenernos avantes viviendo el día a día de calamidades y a la vez ir construyendo otro modo de relacionarnos. Para esto fue necesario transitar a un modo cotidiano de vida desde un compromiso ético-político. Aprendiendo a arriesgar la vida mirándome como una ciudadana más. Sabiendo que no somos los profesionales de la salud mental o la psicología quienes transformamos la sociedad. La acción más importante la hace el pueblo y nosotros como parte de él, que desde su sabiduría se cuida, protege, avanza. Y además encontré que lo hacen muchas veces utilizando una mirada llamada entre colegas enfoque psicosocial.

\section{2) I nterculturalidad. Diálogo intercultural como el camino a un modo integral y complejo de conocer nuestro entorno.}

He atravesado un recorrido que parte de una disciplina, en este caso la psicología, y que me ha llevado a ver la importancia de la multidisciplinariedad e interdisciplinariedad. Sin embargo considero necesario afianzar un paso más. Se trata de entablar un diálogo más estrecho con las diversas ciencias, de tal manera que un mismo problema a enfrentar sea analizado desde diversos modos del conocer. Logrando una respuesta integral, holística y más eficaz.

Para ello creo necesario plantearme cómo vivir en la interculturalidad. Esfuerzo decisivo para salvar obstáculos cotidianos como desarrollar intervenciones de adultos hacia jóvenes, de universitarios hacia comunidades campesinas mayas. Cada día por la ciudad de San Cristóbal, Chiapas convivimos al menos tres culturas, los maya-tsotsiles, los chiapanecos y europeos. Esa es nuestra realidad, de ella partimos, no podemos obviarla ya que trasciende cualquier acción a desarrollar. En mi trabajo cotidianamente me encuentro en relación con tres culturas o más a la vez, tres o más cosmovisiones, proyectos políticos o generaciones.

Entiendo así que una exigencia es aprender a dialogar ya que generalmente son monólogos los que presenciamos, dejando fuera al grupo social más vulnerable, generalmente los pueblos originarios. Entonces reconozco la importancia de extender un diálogo que llamo intercultural desde diversos ámbitos: 1) Idiomas; 2) Cultura; 3) Modo de conocer, sabidurías, ciencias, disciplinas; 4) Ideología o posición política; 5) Generacional; 6) Urbano-rural.

\section{Contradicciones y Tensiones}

A lo largo de nuestra experiencia de trabajo nos hemos encontrado con muchos dilemas. Vivimos entre muchas contradicciones. Algunas son pasajeras pero otras permanecen en el tiempo. Nuestro reto es aprender a convivir con ellas y tomar decisiones buscando ser fieles a nuestros principios éticos. Algunas de ellas son:

\footnotetext{
${ }^{19}$ Chávez-Tafur J. Aprender de la experiencia. Una metodología para la sistematización. Fundación ILEIA/Asociación ETC Andes. Lima, Perú. 2006.
} 
Cubrir las emergencias versus construir en el largo plazo. Esta es una tensión muy difícil para mí de afrontar y así lo encuentro en muchos esfuerzos organizativos. En nuestros países vivimos una emergencia permanente, por esa razón es aún más significativo nuestro mirar psicosocial que posibilita la multiplicación de una acción a la vez que la enfrenta. En los primeros días de mayo de este año en Atenco, estado de México en el centro del país, el Estado Mexicano realizó una acción policiaco-militar en contra de vendedores floristas, campesinos del Frente de Pueblos en Defensa de la Tierra y adherentes de La Otra Campaña. Resultando dos jóvenes asesinados por la policía, más de doscientos detenidos hombres brutalmente golpeados y mujeres torturadas salvajemente bajo agresiones sexuales. El proceso organizativo nacional recientemente iniciando con La Otra Campaña sufrió un golpe importante, ya que implica un proceso de construcción de relaciones de confianza. Pasaron algunos meses y ya el modo de afrontamiento pasó de la respuesta inmediata a la de construcción a largo plazo. Esto mismo le sucede al vecino estado de Oaxaca con más de seis meses de movilización social en un levantamiento popular sin precedentes. El Estado Mexicano decide hacer uso de la violencia institucional. La APPO y el pueblo oaxaqueño en general tienen el gran desafío de pasar de la defensa al fortalecimiento de su estructura organizativa y en esa batalla se encuentran actualmente.

Para ejemplificar aún más. Cuando estoy escribiendo estas líneas, recibí una llamada que me puso en alerta para buscar a una persona detenida. Establecí comunicación con nuestra red local para iniciar la búsqueda. Al poco tiempo supimos que ya había sido liberada y todas y todos volvimos a nuestras tareas previstas. De lo contrario, teníamos que implementar una acción inmediata, decidir quienes salían a buscarlo proveerle una defensa. Claro teniendo una red local es mucho más rápida cualquier búsqueda. De ahí la importancia de construir nuestra organización local y fortalecer vínculos de confianza.

Otra tensión relacionada a la anterior es la de impulsar acciones específicas que implican menos preparación sin participación popular versus acciones complejas e integrales que llevan tiempo en su planeación impulsando la participación popular.

Estas tensiones como se ha mencionado van a resolverse de una u otra forma según el caso y la opción que tomemos. Así sucede entre el tiempo y modo en que realizamos nuestro compromiso político-social, nuestra vida familiar y laboral.

Otra tensión común es la que se refiere a ser fiel a nuestras convicciones versus seguir modelos ajenos. Por ejemplo, caminar desde las estrategias y ritmo de la población o caminar desde las estrategias y ritmo de las agencias financieras.

Algunas más: 1) Abordar la salud mental a profundidad en pequeñas poblaciones versus dedicarnos a la salud mental comunitaria llegando a más sectores. 2) Trabajar en equipos con quienes tengo códigos comunes avanzando velozmente o en equipos que no trabajan la salud mental en donde debo ajustarme al propio ritmo del equipo. 3) Trabajo de equipo versus trabajo individual. 4) Centrarse en tareas locales o globales, de incidencia más allá de nuestra propia región y 5) todas aquellas que surgen al tomar una opción que invariablemente deja atrás otros caminos.

\section{Papel Histórico de la Psicología Social de la Liberación Ante los Desafíos del Siglo XXI}


Nuestra historia reciente en Chiapas son doce años de guerra. Pero nuestra historia, analizada desde una perspectiva sistémica, nos habla de más de 400 años de una guerra de exterminio. Exterminio del sistema-mundo mesoamericano (Aubry A., 2006). Los mismos siglos en los cuales el modo de producción capitalista se convierte en un sistema social y económico mundial, se consolida el sistema-mundo capitalista. En palabras de Wallerestein:

"En uno de mis libros recientes, titulado "The End of the World as we Know it. Social Science for the Twenty First Century", he argumentado que el moderno sistema-mundo está aproximándose a su fin, y está entrando en una época de transición hacia algún nuevo sistema histórico, cuyos perfiles no conocemos ahora, y no podemos conocer por adelantado, pero cuya estructura si podemos ayudar en cambio a construir de manera activa. El mundo que hemos conocido ha sido el de una economía-mundo capitalista, y este mundo está siendo sometido a ciertas presiones estructurales a las que ya no está en posición de controlar." ${ }^{\prime 2}$

Este autor menciona tres presiones estructurales. "La primera es a consecuencia del proceso de desruralización del mundo, que está ahora muy avanzado y que probablemente se habrá completado totalmente dentro de los próximos veinticinco años. Es un proceso que está incrementando inexorablemente el costo del trabajo en tanto que magnitud porcentual del valor total creado. La segunda presión es la consecuencia de largo plazo de la externalización de los costos, que ha sido llevada hasta el agotamiento ecológico. Ello está haciendo aumentar el costo de los insumos dentro del porcentaje del valor total creado. Y la tercera presión es la consecuencia del proceso de crecimiento de la democratización en el mundo, que ha conducido al desarrollo de demandas constantemente crecientes respecto al gasto público en educación, salud y garantías del ingreso de vida. Esto está impulsando hacia arriba los costos de los impuestos en el porcentaje del valor total creado. La combinación de estas tres presiones está creando una enorme reducción estructural, a largo plazo, de las ganancias derivadas de la producción, hasta el punto de estar transformando al sistema capitalista en un sistema no rentable para los propios capitalistas." ${ }^{21}$

Retomando otro modo de análisis, el del movimiento indígena zapatista en México: "vemos que el capitalismo es el que está más fuerte ahorita. El capitalismo es un sistema social, o sea una forma como en una sociedad están organizadas las cosas y las personas, $y$ quien tiene $y$ quien no tiene, y quien manda y quien obedece. En el capitalismo hay unos que tienen dinero o sea capital y fábricas y tiendas y campos y muchas cosas, y hay otros que no tienen nada sino que sólo tienen su fuerza y su conocimiento para trabajar, $y$ en el capitalismo mandan los que tienen el dinero y las cosas, y obedecen los que nomás tienen su capacidad de trabajo. ${ }^{122}$

..."y el neoliberalismo pues es la idea de que el capitalismo está libre para dominar todo el mundo y ni modos, pues hay que resignarse y conformarse y no hacer bulla, o sea no rebelarse... El neoliberalismo tiene sus planes económicos, políticos, militares y culturales. En todos esos planes de lo que se trata es de dominar a todos, y el que o obedece pues lo reprimen o lo apartan para que no pase sus ideas de rebelión a otros. ${ }^{123}$

\footnotetext{
${ }^{20}$ Wallerstein I. Los intelectuales en una época de transición. P. 19

${ }^{21}$ Idem. P. 19 Para profundizar véase: Utopística o las opciones históricas del siglo XXI, Ed. Siglo XXI, México, 1998.

${ }^{22}$ Sexta declaración de la selva lacandona. 2005 parte III de cómo vemos el mundo.

${ }^{23}$ Idem.
} 
"Entonces como que el capitalismo destruye a los países que conquista con la globalización neoliberal, pero también como que quiere volver a acomodar todo o hacerlo de nuevo pero a su modo, o sea de modo que lo beneficie y sin lo que le estorba... destruye lo que hay en esos países, destruye su cultura, su idioma, su sistema económico, su sistema político, y también destruye los modos en que se relacionan los que viven en ese país. $O$ sea que queda destruido todo lo que hace que un país sea un país...Pero no es tan fácil para la globalización neoliberal, porque los explotados de cada país pues o se conforman y no dice que ya ni modo, sino que se rebelan; y los que sobran y estorban pues se resisten y no se dejan ser eliminados... así como hay una globalización neoliberal, hay una globalización de la rebeldía. ${ }^{124}$

Nos encontramos en el siglo XXI. Los desafíos para la humanidad son múltiples y complejos. Por lo tanto:

1. Para afrontar una guerra se requiere de un pueblo que asuma esta tarea, un pueblo que a la vez supere su herencia histórica: el fatalismo latinoamericano.

2. Se necesita transformar no solamente la estructura de nuestros Estados-Nación (justicia, económica, política) y lograr cambios psicociales. Se trata de acabar con el sistema social capitalista y transitar-construir otro sistema-mundo. Porque "Otro mundo es posible. Otro mundo es necesario" (Lema del 70 Congreso de Psicología Social de Liberación).

3. La mirada psicosocial tiene respuestas y aportaciones ante lo que implican las guerras de todo tipo y sus consecuencias, tiene modos para transformar este fatalismo latinoamericano del que somos herederos. $Y$ tiene planteamientos de construcción de una nueva sociedad, otro sistema-mundo.

4. Las aportaciones de la mirada psicosocial pueden fortalecer y lograr la resistencia a los movimientos de liberación de todo tipo, desde los movimientos político-militar, a los basados en la espiritualidad; los que buscan la salud o los movimientos de derechos humanos.

\section{¿Por qué? Por qué la Mirada Psicosocial Tiene Respuestas Ante el Caos, la Incertidumbre, el Cambio Estructural de un Sistema-mundo?}

Porque la mirada psicosocial surge del horror, del caos, del sinsentido de la violenciatortura-guerras-masacres... Reconoce que el horror es real y duele, duele tanto pero tenemos que mirarlo. Mirarlo y nombrarlo para que nunca más le suceda a otr@s.

Porque nuestro acercamiento a la realidad es desde la complejidad. Enfrentamos día a día lo complejo de la vida social, esa gran vitalidad, irregularidad, movimiento, caos. Caminamos sin certezas. Así caminan las clases peligrosas, los oprimidos, cuya única certeza es saber que moriremos. Porque la certeza que nos anima es que caminamos con lo que hay. Avanzando desde las circunstancias que se tengan. Donde todo puede pasar.

En estos planteamientos radica la posibilidad de afrontar positiva y constructivamente una nueva sociedad.

\footnotetext{
${ }^{24}$ Idem.
} 
Las intervenciones psicosociales reconocen y conviven en la diversidad, la agilidad, creatividad, utopística. Trabajan a partir de lo posible. Busca los desafíos, caminan en ellos. No buscan el poder para abusar sino para crecer y avanzar. Tampoco usan el victimismo. Se trabaja desde el dolor buscando la vida. Su motor es la indignación.

Este modo de trabajo va más allá de un planteamiento ideológico o político, mira la humanidad misma. Danza con la vida desde una mirada esperanzadora. Vuelve al origen de la humanidad: una identidad colectiva, nosótrica (Lenkersdorf, 2004). No como la suma de individualismos, sino como la interacción dialéctica individuo-colectivo, rompiendo el corazón mismo del capitalismo que es igual a individualismo. Las sociedades, las comunidades con una subjetividad nosótrica serán las que sobrevivan y construyan ese otro mundo posible, necesario que vendrá.

\section{¿Cuál es Entonces Nuestro Desafío?}

Seguir nuestro camino compartiendo estos aportes. Para poner nuestros saberes sobre la mesa y sean retomadas por los actores sociales, se requiere un diálogo. En ese diálogo deberemos tener muchas virtudes para que seamos escuchadas. Ya que es un diálogo intercultural complejo que contemple las diferencias en cuanto a: idiomas lingüísticos, culturas, ideologías y posturas políticas, generacionales, ubicación geográfica, ubicación urbano-rural. Y enfáticamente digo, las diferencias en cuanto a origen del conocimiento, sabidurías, disciplinas, ciencias.

Entonces, por un lado tenemos como reto encontrarnos con quienes ya hacen una acción psicosocial sin llamarle así. Ayudar a que la reconozcan, ubiquen el impacto de su trabajo y le den sentido a su práctica cotidiana de activistas o académicos. Si la reconocen, la reforzarán, la alimentarán, buscarán profundizar en ella y tendríamos puertas abiertas para continuar nuestro diálogo.

Otro reto es encontrarnos con los movimientos sociales que ya retoman la mirada psicosocial en sus acciones y retoman la liberación de los pueblos. Encontrarnos desde los diferentes puntos de donde partimos para alimentar los pasos a la liberación.

El tercero y muy significativo para el ámbito académico, tiene que ver con la epistemología de las ciencias. Promover este diálogo entre diversas disciplinas, entre ciencias físicas-naturales, filosofía y humanidades ofrecer nuestros aportes. $Y$ al hacer este diálogo, hacerlo con la visión de sentar bases para tener una epistemología holística, integral o unificada.

San Cristóbal de Las Casas, Chiapas México. Noviembre 2006.

Nota biográfica: Psicóloga originaria de Chiapas, México. Correo electrónico: pagasarri@prodigy.net.mx 


\section{Referencias}

Pérez-Sales P., Santiago-Vera C., Alvarez-Díaz R. Ahora apuestan al cansancio. Chiapas: fundamentos psicológicos de una guerra contemporánea. Centro de Derechos Humanos Miguel Agustín Pro J uárez y Grupo de Acción Comunitaria. México, 2002.

Martín-Baró I. Psicodiagnóstico de América Latina. El Salvador. 1972.

Martín-Baró I., Blanco A. (Ed) Psicología de la liberación. Editorial Trota. Madrid. 1998.

Martín-Baró I. (Ed) Psicología social de la guerra. UCA editores. 1990.

Martín-Beristain C. Enfrentando las tragedias. En Psicología social y violencia política. ECAP. Guatemala. 2001. P.144

Avia MD, Vázquez C. Optimismo Inteligente. Alianza Editorial. Madrid. 1998.

Wallerstein I. Conocer el mundo, Saber el mundo. El fin de lo aprendido. Una ciencia social para el siglo XXI. Siglo XXI editores. 2a edición en español. México. 2002.

Galtung J. Transformar y trascender los conflictos. Edit. Quimera. México. 2004.

Dobles I. Psicología Social desde Centroamérica: retos y perspectivas. Revista Costarricense de Psicología, 1986, número 8 y 9.

Scott Peck M. La nueva Psicología del amor. EMECÉ. Argentina. 1986.

Marina J A, Válgoma M. La lucha por la dignidad. Teoría de la felicidad política. ANAGRAMA. Barcelona. 2000. 1a edición.

Paoli A. Educación, autonomía y lekil kuxlejal: aproximaciones sociolingüísticas a la sabiduría de los tseltales. UAM-Xochimilco. México. 2003

Dobles I. Hacer psicología en Centroamérica. En Subjetividad y política. ILAS. Chile. 1997.

Todorov T. Los abusos de la memoria. Paidós Asterisco. España. 2000. P. 25. 1a edición en francés 1995.

Chávez-Tafur J. Aprender de la experiencia. Una metodología para la sistematización. Fundación ILEIA/Asociación ETC Andes. Lima, Perú. 2006.

Lenkersdorf C. Conceptos tojolabales de filosofía y del altermundo. Plaza y Valdés editores. México. 2004.

Lenkersdorf C. Filosofar en clave tojolabal. Plaza y Valdés editores. México. 2005.

Aubry A., Chiapas a contrapelo. Una agenda de trabajo para su historia en pespectiva sistémica. Centro de estudios, información y documentación Immanuel Wallerstein y Contrahistorias. México. 2005.

EZLN. Sexta Declaración de la Selva Lacandona. México.2005. 
Pérez-Sales P. Reconceptualizar la psicología del trauma desde los recursos positivos: una visión alternativa. Diplomado presencial "Salud Mental en contextos de violencia política y catástrofes. Madrid. 2000.

Martín-Beristain C. Reconstruir el tejido social. I caria. España, noviembre 1999.

Wallerstein I. Utopística o las opciones históricas del siglo XXI. Siglo XXI editores. México. 1998.

Wallerstein I. Los intelectuales en una época de transición. Centro de documentación y difusión de sociología crítica. México. 2005.

Wallerstein I. Abrir las ciencias sociales. Comisión Gulbenkian para la reestructuración de las ciencias sociales. Siglo XXI editores. 2006. 1a edición1996.

Wallerstein I. Impensar las ciencias sociales. Siglo XXI editores. 2004. 1a edición 1998. 